IZA DP No. 8376

Social Protection beyond the Bottom Billion

Susan Murphy

Patrick Paul Walsh

August 2014

Forschungsinstitut zur Zukunft der Arbeit Institute for the Study of Labor 


\title{
Social Protection beyond the Bottom Billion
}

\author{
Susan Murphy \\ Trinity College, Dublin \\ Patrick Paul Walsh \\ University College Dublin \\ and IZA
}
Discussion Paper No. 8376
August 2014

IZA
P.O. Box 7240
53072 Bonn
Germany

Phone: +49-228-3894-0

Fax: +49-228-3894-180

E-mail: iza@iza.org

Any opinions expressed here are those of the author(s) and not those of IZA. Research published in this series may include views on policy, but the institute itself takes no institutional policy positions. The IZA research network is committed to the IZA Guiding Principles of Research Integrity.

The Institute for the Study of Labor (IZA) in Bonn is a local and virtual international research center and a place of communication between science, politics and business. IZA is an independent nonprofit organization supported by Deutsche Post Foundation. The center is associated with the University of Bonn and offers a stimulating research environment through its international network, workshops and conferences, data service, project support, research visits and doctoral program. IZA engages in (i) original and internationally competitive research in all fields of labor economics, (ii) development of policy concepts, and (iii) dissemination of research results and concepts to the interested public.

IZA Discussion Papers often represent preliminary work and are circulated to encourage discussion. Citation of such a paper should account for its provisional character. A revised version may be available directly from the author. 


\section{ABSTRACT}

\section{Social Protection beyond the Bottom Billion*}

Most conceptualisations of the bottom billion assume that "the poor" are a minority group in a state of continuous dependency, identifiable by region and demographic. Using a flow analysis (inflow and outflow) of poverty, rather than a stock analysis, we explain why poverty is more appropriately understood as a dynamic, with the majority of people flowing in and out of poverty for short durations. Distinguishing between structural and transitory poverty gives rise to a focus on the identification of multiple constituencies in the wider population including the permanently poor; sometimes poor; and non-poor. External shocks, including economic and environmental shifts, and risks such as ill-health, can affect any individual, household, or population in a non-predictable way, and can lead to loss of livelihood and a descent into poverty for various durations. At any point in time the bottom billion is made up of a blend of both transitory and structural elements with the former reflecting poverty as a risk for a much wider population than is often assumed. Using this analysis, the total stock of poverty potentially entails up to 5.1 billion people who do not have access to comprehensive social protection systems and are therefore vulnerable to spells in poverty. To protect against shared risks and mutual vulnerabilities, this paper argues that global insurance instruments, regulated through domestic institutions, would provide an efficient solution to transitory poverty. Further, it argues that these instruments could provide a foundation for investment in more equitable and extensive social protection measures that could target the multiple dimensions of structural poverty thereby seeking to ensure that no one is left behind.

JEL Classification: 035, 043, J65, J68

Keywords: social protection, social security, social insurance, social transfers, social justice, transitory poverty, structural poverty, Pareto efficiency, equity

Corresponding author:

Patrick Paul Walsh

University College Dublin

School of Politics and International Relations

G311 Newman Building

Belfield

Dublin 4

E-mail: ppwalsh@ucd.ie

\footnotetext{
* Paper presented at the first annual International Conference on Sustainable Development Practice in Columbia University in New York, September 2013. Paper was also presented at the Dublin SDSN Lab seminar series in University College Dublin in October 2013. We are grateful for the feedback on the paper.
} 


\section{Introduction}

According to the World Bank, it is expected that 84 countries will achieve the first Millennium Development Goal (MDG) to halve poverty by 2015, where poverty is measured as the proportion of the population living below $\$ 1.25$ purchasing power parity (PPP) per day. However 1.2 billion people still remain below the poverty line in $2012 .{ }^{1}$ While poverty rates are declining the concept of the bottom billion survives. At the beginning of the MDG project, the bottom billion entailed one in six people globally. In 2012, the bottom billion now represents one in seven people living in extreme poverty and thus remains a pressing problem and focus of concern as negotiations continue on what should follow the MDGs.

According the 2013 report from the UN High Level Panel of Eminent Persons developed to inform the post-MDG/2015 discussions, A New Global Partnership:

The next development agenda must ensure that in the future neither income nor gender, nor ethnicity, nor disability, nor geography, will determine whether people live or die, whether a mother can give birth safely, or whether her child has a fair chance in life. (2013, p. 7).

This report calls on world leaders and international organisations to embrace a “transformative shift” that sets a shared global obligation to "leave no one behind” (ibid). This is a bold and ambitious requirement. It sets a strong ethical requirement to reject principles that seek to maximise the interests of the greatest number of people, instead setting the requirement that all should benefit from future development interventions, and no one should be left behind.

The problem we highlight in this paper is that much policy analysis continues to assume that it is possible to clearly define poor and non-poor as separate identifiable groups within a population. Our analysis suggests that poverty is a dynamic with regular movements in and out of the states of poor and non-poor. These dynamics are present for at least three reasons. First, the majority of the people living in developing countries have weak and incomplete government provided social protection systems and are, therefore, at risk of a descent into poverty of various durations at any time. ${ }^{2}$ All populations are exposed to nonpredictable external shocks, including economic and environmental shifts, and risks such as

\footnotetext{
${ }^{1}$ See http://www.thelancet.com Vol 382, accessed 3 August 2013

${ }^{2}$ ILO (2014) report that only 27 per cent of the global population have access to comprehensive social security systems, even though the ILO Social Protection Floors Recommendation, 2012 (No. 202), reflects a consensus on the extension of social security reached among governments and employers' and workers' organisations from 185 countries at all levels of development and is endorsed by the G20 and the United Nations.
} 
ill-health, that can lead to loss of livelihood and a decent into poverty for various durations of time. ${ }^{3}$ Second, supports provided by religious and donor organisations have uneven scope and coverage. Although an important safety net for many of the poorest communities, such supports do not represent a sustainable solution for wider populations all of whom share similar risks to external shocks, ill health, and sudden loss. Finally, traditional risk pooling self/community-help supports are weakening with the onset of rapid urbanisation. ${ }^{4}$

In this paper we argue that when poverty is analysed as a dynamic flow, transitory poverty is a dominant feature of the stock at any given time. Temporary spells below the poverty line are experienced by a broad cross section of society. We argue that the risk of extreme poverty goes beyond the bottom billion and that up to 5.1 billion people who lack adequate social protection systems are exposed to finite or transitory spells of poverty, flowing in and out of poverty for finite durations. In what follows, we argue that social protection institutions are required to prevent and cure transitory inflows into poverty. These can be efficient social security schemes based on a contributory model by households and companies, underwritten by governments. Exposure to common risks, variance in risk aversions, and assessments and differences in incomes provide a market for social security products that can lead to Pareto efficient improvements which protect households and prevent the flow of the some-times poor and non-poor into poverty. Further, we argue that such social protection funds and systems could provide the basis for increasing equity through extensive non- contributory social transfers to excluded groups and those experiencing structural poverty, thereby ensuring that no one is left behind. Taking the alleviation of all forms of poverty as the fundamental motivation of development intervention, this paper explains how efficient social insurance instruments can be harnessed to protect against the risk of poverty whilst also targeting equitable outcomes that aim to ensure that no one should be left behind. Rather than seeking to achieve the greatest outcomes for the greatest number, this approach proposes practical measures for an inclusive model which seeks to ensure that all members of a community share in the benefits of social cooperation.

Our approach is motivated by a fundamental axiom of logic, that ought implies can. States must have sufficient capacities to meet this requirement if the obligation is to hold.

\footnotetext{
${ }^{3}$ Word Bank Development Report (2014) documents the extent that global populations are vulnerable to such risks.

${ }^{4}$ Devereux and Lund (2010) outline three components of welfare in Africa and argue that the state should take full responsibility for delivery of such services. However, they also argue that the state should be democratic and sensitive to historically modalities that still exist today when transitioning to state run schemes.
} 
Rather than focusing on "floors" as per the proposals of the International Labour Office (2011), in what follows, we argue that systems should simultaneously provide protection to those at risk of descent into poverty. Offering the opportunity for insurance against risk can generate a sustainable solution as those in a position to contribute can do so, and funds can be made available to support those in need, recognising that all persons will face similar needs over the course of their lives. Thus, we propose harnessing "natural” inequalities (such as age, capacities, and exposure to risk) to reduce social inequalities (ability to contribute, preference for insurance, gender, resources, and opportunities) thereby prioritising the protection of all those at risk and vulnerable to descent into poverty, and at the same time ensuring that no one is left behind. To stem the dynamics of transitory poverty, we explain how social insurance systems can prevent short-term inflows of people from the "sometimes poor" and "non-poor" categories into poverty. Further, we argue that the overall social protection fund could provide a sustainable source for social transfers and programmes to target outflows from the category of structurally poor. The particular forms of instrument are different for each category. However, in what follows, we explain how a social protection solution can blend financial engineering and social responsibility, using Pareto efficiency to achieve socially optimal outcomes thereby harnessing what might be termed "natural inequalities” to reduce social inequalities, with a particular focus on inclusion and ensuring "no one is left behind".

We explain why the instruments that deal with structural issues for targeted groups are important, but instruments that deal with bad luck that can hit the general population are essential in managing the dynamics of poverty, and stemming fresh inflows below the income poverty threshold. In examining the dynamics of poverty, and proposing solutions to stem the flow into poverty whilst simultaneously investing in equitable social transfers and social protection mechanisms, this paper is relevant to policymakers, government and international organisations, those engaged in systems' changes, and private enterprises with the capacity to deliver trans-state multi-national social insurance products.

Section II begins with an introduction to the problem - contemporary conceptualisations of poverty as a stock rather than flow. We explain how stock analysis can fail to capture the dynamic and fluid nature of transitory poverty, and the risks and vulnerabilities of all uninsured, unprotected, insecure human beings. Section III examines the idea of social protection, what this is, how it can be justified, and why this is an appropriate, and indeed essential instrument to stem fresh inflows into poverty. It also argues that such 
instruments are both the right and the smart solution to pursue. ${ }^{5}$ In Section IV we explain how such a model might work within country and in a global setting, both in terms of the demands of Pareto efficiency and in generating the conditions whereby greater equity can be achieved and the most vulnerable can be protected. We argue that this model can create financial space for investment in the social and human capital requirements of the most vulnerable individuals, households, and groups. We examine a number of potential objections to this approach in Section V. Section VI concludes.

\section{The Problem - contemporary conceptualisations of poverty as a stock}

As Amartya Sen has observed, “... the most common and traditional measure of poverty has tended to concentrate on head counting” (1999, p. 362). Poverty is most widely measured as a stock. Chen and Ravallion (2008), explain that the numbers in poverty, at any point in time, are highly sensitive to the thresholds that define “extreme poverty".

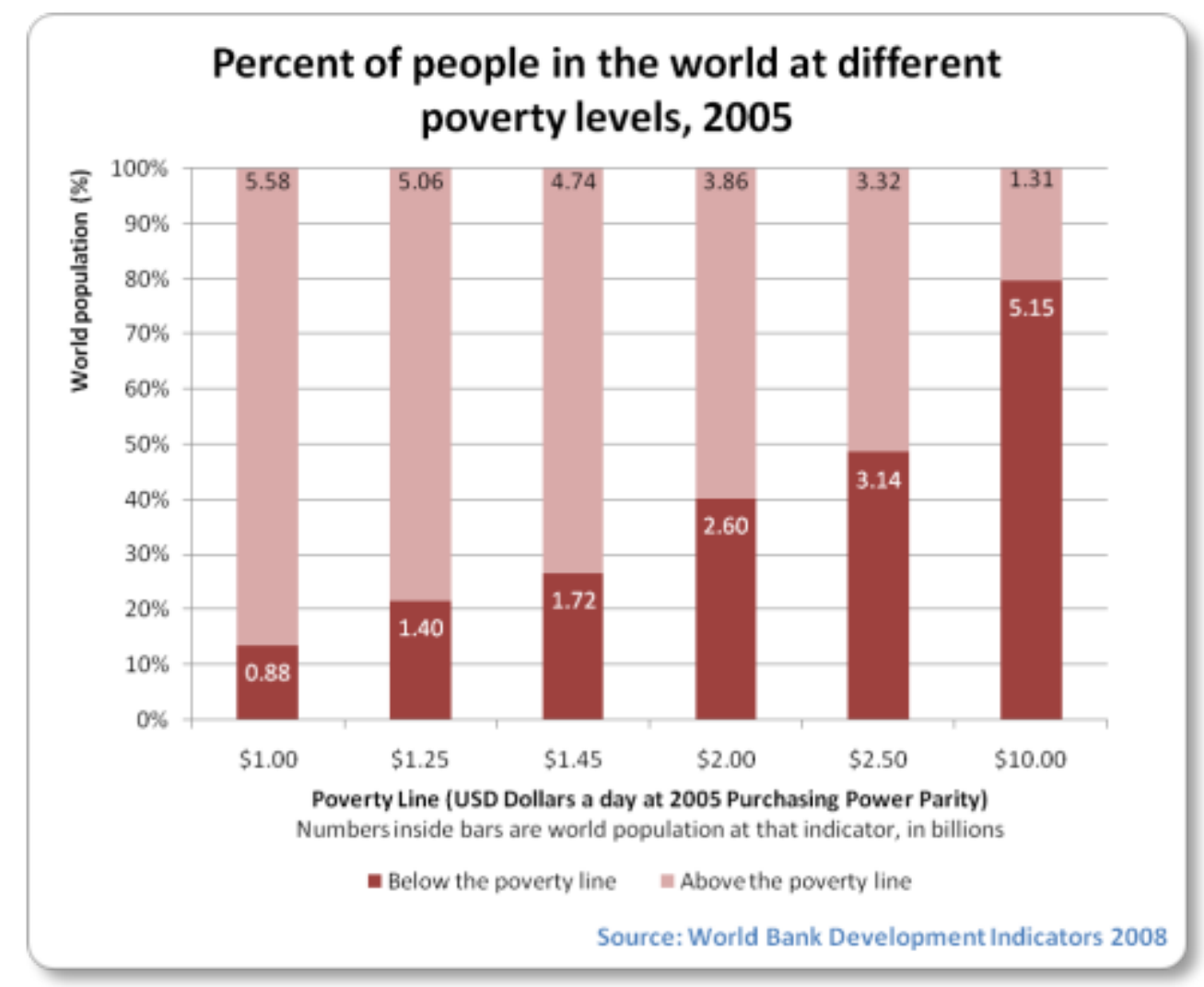

\section{Figure 1}

As outlined in Figure 1, when the threshold is set at \$1.25 (PPP) per day the numbers in income poverty in 2005 are 1.4 billion individuals. However, this figure jumps to half of

\footnotetext{
${ }^{5}$ The phase "right and smart" is borrowed from the UN HLP report (2013).
} 
the global population when we use a threshold of \$2 (PPP) per day. The reality is that 80 per cent of the global population live on less than \$10 (PPP) per day. The margins that define people as poor and non-poor are very narrow. While thresholds raise an interesting issue, in this paper we are more concerned with poverty dynamics. During the course of a defined period of time individuals can make dramatic movements across the income distribution and thresholds.

As Krishna explains, measuring poverty as a stock entails “... considering the numbers of poor people at a particular moment in time. Such stocks can be compared across two points in time and the net change calculated. [However] such analysis does not [indeed cannot] reveal how this change was derived: how many people fell into poverty within the specified time frame and how many others concurrently escaped" (2007, p. 1). An analysis of poverty dynamics examining inflows and outflows reveal the mobility of groups. In simple terms, extreme poverty can be an experience of the broader population and is not confined to a single population cohort.

Contemporary conceptualisations and measures of poverty typically define "the poor" and "the non-poor" as static groups, identifiable by region and demographic group. Debates in both academic and policy literature widely assume that such groups are socially constructed, and not a natural outcome of differing levels of productivity and ability, or indeed, a stochastic outcome. In reality extreme poverty is not experienced by the same bottom billion of the population. Rather there is ongoing mobility between income groups where extreme poverty, for various durations, is a risk for the vast majority of the population in the developing world.

Without disputing the importance of livelihood creation for social and economic development, it is also important to consider livelihood protection. Human beings can suffer endowment/asset and hence income losses if ill- health hits, or food prices shift, or an environmental shock renders a place or type of employment non-viable. ${ }^{6}$ Vulnerability to loss of livelihoods and inflows into poverty are a key driver of poverty dynamics and yet are sometimes overlooked in debates on poverty alleviation. In fact, the dynamics of poverty

\footnotetext{
${ }^{6}$ Tanner and Mitchell (2008) see social protection as targeting the general population to best assist people who shift in and out of poverty, with different needs at different points in time
} 
involve a far greater reach of households across the population, the implications of which are not well understood. ${ }^{7}$

The distinction between poverty understood as a permanent stock and poverty understood as a dynamic with inflows and outflows (of different durations), is critical to understanding the fundamental nature of poverty. The stock reflects both transitory and structural elements of poverty. Inflows reflect the levels of vulnerability and risk associated with livelihoods across a broad cross section of the population. Outflows reflect spells in poverty that are more transitory than structural. Overall a flow analysis of poverty allows one to distinguish between structural and transitory poverty, and determine varying levels of vulnerability to descent into poverty and varying ability to exit within the general population. The following equation identifies the change in the stock of poverty, $\Delta \boldsymbol{S}_{t}$, in any time frame as the difference between the number of inflows, $\boldsymbol{I}_{t}$, over the outflows, $\boldsymbol{O}_{t}$, over the defined period.

$$
\Delta S_{t}=I_{t}-O_{t}
$$

Annual flows dictate the change in the level and composition of poverty. In theory the change in the stock can be generated by an infinite number of turnover rates. A change in the stock by positive ten can be due to ten people entering and zero exits, over a year. It is also consistent with one billion and ten entrants and one billion exits over the same period. The former has long durations of a year while the latter would have spells of less than one year. The former are spells without an exit, which appear more structural, while the latter has finite spells that are more transitory.

There are important questions regarding the source of these inflows. Are inflows reflecting structural or transitory issues? Does the spell itself create a path dependency that turns what should have been transitory into a structural problem? If inflows are coming from the general population, and the stock is made up of people that are more transitory in their state than structural, then this would undermine the conventional way of understanding poverty and would require a different policy focus. In practice the stock will consist of various inflow histories of various durations. The stock is likely to have a bias towards long-

\footnotetext{
${ }^{7}$ Typical analysis that informs the contemporary debates focuses on growth in the stock of "the poor". It is argued that the inflow into poverty is driven by high birth rates in low-income locations and households. Second, that these inflow rates exceed the outflow rate from poverty which would include mortality rates. Thus, absolute levels of poverty in identifiable groups increase, even if poverty rates in terms of the total population declines. However, evidence suggests that poverty inflows, duration, and outflows are far less structural and identifiable by group than assumed.
} 
term durations, however, short-term incomplete durations can account for a large percentage of the stock when transitory poverty is a feature of the general population experience. From a policy perspective:

1. Preventing inflows, or inducing outflows of various durations, can target very different problems and groups of households.

2. Different groups may require different forms of social protection that both prevents and helps exit from poverty.

The ILO policy paper, Social Protection Floor: For a Fair and Inclusive Globalisation (2011) makes the following statement.

Current statistics speak eloquently of widespread poverty and deprivation. About 5.1 billion people, 75 per cent of the world population, are not covered by adequate social security (ILO) and 1.4 billion people live on less than US\$1.25 a day (World Bank)’.(2011: xxi)

The issue we are raising is that the 1.4 billion at any point in time may not be the same people and hence cannot be the sole target of policy. In reality we have 5.1 billion with potential and realised spells in poverty and hence policy should shift to this reality. The reasons why one might fall into poverty are multiple, but the probability of a spell in poverty will not be a completely random event. Following Sen's analytical framework to explain the causes of famine (Poverty), using the failure of the mechanisms behind the First Welfare Theorem (pathways to Pareto efficiency), we see that exposure to poverty depends not only on the discriminatory nature of shocks, but also on the initial position of households in terms of endowments (assets/income) and entitlements (access to goods; access to protection). Therefore, instruments to protect against shocks, as well as instruments to improve the initial position of households such as opportunities for employment, are both required to stem fresh inflows into poverty, and support a sustainable, thus permanent, exit from poverty.

Conceptualising poverty as an identifiable stock does not extend any consideration to the stochastic events that occur over the duration of a human life. For all human beings, life is precarious and uncertain. Accidents happen, ill-health hits, and natural shocks occur. These are matters of sheer brute luck to which every human being, as a finite and vulnerable entity, is exposed. External shocks, including economic and environmental shifts, and risks such as ill-health, can affect any individual, household, or population in a non-predictable way, and 
can lead to loss of livelihood and decent in to poverty. From an economic perspective, formal market economies cannot function if individuals do not have capacities to insure their assets and protect their investments and livelihoods. From a moral perspective, an individual's lifeopportunities should not be determined by morally arbitrary factors such as a flood or accident. Distinguishing between structural and transitory drivers of poverty gives rise to a focus on the identification of different constituencies (permanently poor; sometimes poor; and never poor); characterised by different vulnerabilities (causes of inflow); indifferent structural problems (deterrents to outflow); and which require different instruments and coping strategies. The following table, although representative of a stock, gives some indication of the dynamic nature of poverty through the structure of questions.

Table 1.1 Percentage of households who are: always poor, sometimes poor, never poor

\begin{tabular}{|c|c|c|c|c|}
\hline Countries & $Y_{\text {ears }}$ & Alwrys poor & Sometimes poor & Nerer poor \\
\hline China & $1985-90$ & 6.2 & 47.8 & 46.0 \\
\hline Côte d'Ivoire & $1987-88$ & 25.0 & 22.0 & 53.0 \\
\hline Ethiopia & $1994-97$ & 24.8 & 30.1 & 45.1 \\
\hline India & $1975 / 76-1983 / 84$ & 21.9 & 65.9 & 12.4 \\
\hline Indonesia & $1997-98$ & 8.6 & 19.8 & 71.6 \\
\hline Pakistan & $1986-91$ & 3.0 & 55.3 & 41.7 \\
\hline Fussian Federation & $1992-93$ & 12.6 & 30.2 & 57.2 \\
\hline South Africa & $1993-98$ & 22.7 & 31.5 & 45.8 \\
\hline Viet Nam & $1992 / 93-1997 / 98$ & 28.7 & 32.1 & 39.2 \\
\hline Zimbabwe & 1992/93-1995/96 & 10.6 & 59.6 & 29.8 \\
\hline
\end{tabular}

Source: Cited by Subbara, 2002. While the data for this study was collected some time ago, the essential point that this table conveys is unchanged - that a large proportion of people fall in and out of poverty.

From this table it is possible to identify large numbers of people who would claim that they are "sometimes poor", that is, for one reason or another, they experience finite spells of income poverty. The distinction between structural and transitory poverty is critical when selecting appropriate instruments, interventions, and policies. As Grootaert, Kanbur, and Oh (1995) note, those experiencing permanent exclusion from the formal workforce may need targeted programmes to enhance their human and physical capital endowments; those excluded from the workforce on a permanent basis due to disability or old age may require permanent cash transfers in the form of pensions and disability allowances; while those who are unable to find employment or unable to work due to a short term illness, for example, may only require temporary assistance. 
Analysis of poverty that focuses on head counts, with an underlying assumption that "the poor" are a homogenous, static group, identifiable by region and demographic profile, cannot account for the inherently non- predictable and transitory nature of poverty. As Krishna's research indicates, “... not everyone who is poor was born into poverty.... [rather] poverty is constantly being refreshed with two concurrent streams flowing in parallel” (2007, p. 1), with different people moving into and out of poverty at the same time.

So what are the implications of this, and what is the link with persistently high levels of poverty and social protection? In what follows, we argue that a person born in Malawi shares a similar need for social protection as a person born in Malmo or Madrid. When poverty is analysed as a flow rather than a stock, we argue that fresh in-flows below the poverty threshold are most likely to come from the broad group of unprotected individuals, rather than a definitive fixed group. Thus, if development interventions are to achieve their objectives of reducing poverty and protecting the most vulnerable, then they ought to give consideration to this wider group, with its different constituencies, requirements, and vulnerabilities.

\section{The Idea of Social Protection}

\subsection{What is social protection?}

According to Gentilini and Were Omamo, the idea of social protection “... captures how members in societies support each other in times of distress” (2011, p. 329). This idea entails two distinct components - social security or insurance, defined as a reciprocal, contributory fund that people pay into to protect their assets, and receive benefits from as the need arises; and social protection measures, defined as non-contributory social transfers distributed to those excluded from the formal workforce due to age (in the form of pensions and child benefits); ability (disability allowances; maternity cover), and public goods and services. Different individuals, households, and groups will require different instruments and interventions, depending on the context of their needs. ${ }^{8}$

In response to shared risks and mutual vulnerabilities countries in the Global North have all moved towards varying models of social protection that create safety-nets around

\footnotetext{
${ }^{8}$ Devereux and Sabates-Wheeler (2004) state "Today, social protection refers to all public and private initiatives that provide income, consumption or asset transfers to the poor, protect the vulnerable against livelihood risks, and enhance the social status and rights of the marginalised". Thus a welfare state is required to consider both the poor and those vulnerable to poverty.
} 
their communities, and support their social, political, and market systems. Social protection, including contributory and non-contributory instruments, within these locations is typically justified on the basis of solidarity and reciprocity. Solidarity here refers to the recognition of shared human risks and vulnerabilities, and ultimately rests on recognition of the equal moral worth of all individuals. Reciprocity here refers to systems of social cooperation and engagement that all contribute towards, and where the benefits and burdens of such cooperation can be shared across all members of the community.

However, social protection structures are not unique to high income locations. In traditional communities, it is typical for families and extended families to come together in times of need. Thus, informal social protection frameworks of many varieties have been part and parcel of human social existence for many years, particularly in rural areas. Over the last century, non-governmental organisations have engaged in the provision of some social protection instruments and the delivery of public goods and services in many lower-income locations. However, in 2011, 75 per cent of the global population live without social security and social protection supports. In less developed countries and regions, in the absence of such supports, individuals and households must develop coping strategies at a micro level to deal with both natural and social contingencies. Thus, exposure to shocks, even minor shocks such as an illness or a temporary loss of employment, leave the majority of the global population in a state of material insecurity and vulnerable, and to varying degrees, at risk of descent below the poverty threshold. ${ }^{9}$

However, the poorest countries also have the greatest barriers to deploying social protection schemes for a range of reasons including lack of resources, social cohesion and trust, weak political legitimacy, political will, and historical practices. For example, in a number of countries in Sub-Saharan Africa economies are predominantly informal; state infrastructure to facilitate taxation, trade, and employment regulation are weak; and social trust in state institutions is low. As such, there can be substantial economic, social, and political barriers to establishing formal sustainable and state-financed social protection systems. At the same time, the demographic profiles of such locations, with young populations, increasing levels of education, improving health and life expectancies, suggest that the capacity exists for such populations to contribute to a social protection fund, should the opportunity to do so arise. This points to the possibility of a strong market for social

\footnotetext{
${ }^{9}$ Devereux, Ellis, and White (2009) do recognise that social protection provides different needs for various groups. It evens out consumption patterns over shocks to households by ensuring a basic level of income and it also prevents asset loss in times of temporary distress and adverse shocks.
} 
insurance within countries and global partnerships. The reasons for establishing such frameworks are multiple and varied, but underlying all such models is a general acknowledgement that life is precarious and uncertain. Accidents happen and natural events occur. These are matters of sheer brute luck to which every human being, as a finite and vulnerable entity, is exposed. In the global North, rather than adapting to such uncertainty and exposure to such risks through deepening patterns of self-reliance, general practices of insurance, risk-management strategies, welfare bureaucracies, and critical infrastructure supports evolved, engaging private and public entities, to pool the risks and resources, and distribute to participants of schemes as needs arose. ${ }^{10}$ Thus, there are strong moral and economic reasons for investing in the development of robust social protection systems that can support the global population, and not only those born in regions of the Global North.

\subsection{Why Are Social Protection Instruments Required?}

The requirements for social insurance and protection are generated by the contingencies of human life to which every human being is exposed. Many different reasons can be identified to justify social protection systems. Such reasons include moral and ethical justifications; social and political justifications; and economic and prudential justifications.

From a moral perspective, social protection instruments can be explained as practical manifestations of what might be termed, a duty of mutual aid. There are prudential reasons for acknowledging such a duty. For example, situations arise in every person's life when they need the help of others, and so to ignore this duty when others are in need might deprive one of assistance when the need arises. However, there are also reasons to attribute intrinsic value to this duty. As John Rawls has suggested, “... a sufficient ground for adopting this duty is its pervasive effect on the quality of everyday life. The public knowledge that we are living in a society in which we can depend upon others to come to our assistance in difficult circumstances is itself of great value.... The primary value ... is not measured by the help we actually receive but rather by the sense of confidence and trust in other men's [and women's] good intentions and the knowledge that they are there if we need them” (Rawls, 1971, p. 339).

There are further and perhaps weightier moral reasons to seek the establishment of institutions that can provide social protection. All communities are, to a greater or lesser

\footnotetext{
${ }^{10}$ See Duffield (2010) for a critical examination of the "global life-chance divide".
} 
degree, engaged in systems and practices for mutual cooperation and benefit. The matter of distribution of these benefits, and the corresponding burdens, is fundamentally a matter of justice, and an appropriate area for moral evaluation and scrutiny through a justice-based lens. Further, many have argued that there is something essentially unjust when a person's life-chances are determined not by their choices, but by brute luck. ${ }^{11}$ Many liberal egalitarians argue that justice demands that the worst effects of bad luck should be mitigated and therefore, there may be a moral requirement to establish institutional arrangement where these do not exist. ${ }^{12}$ Richard Arneson, for example, has argued that this is a central concern of distributive justice:

"The concern of distributive justice is to compensate individuals for misfortune. Some people are blessed with good luck, some are cursed with bad luck, and it is the responsibility of society - all of us regarded collectively - to alter the distribution of goods and evils that arise from the jumble of lotteries that constitutes human life as we know it” (Arneson, 2003: 103).

However, this does not explain or indicate which principles of justice would be most appropriate to guide in the establishment of such institutions, and to evaluate the performance of these institutions. So, for example, should these institutions aim to deliver maximum benefits to the greatest number? Or should they target protections for the least advantaged. Also, claiming that social protection institutions ought to be established as a matter of justice does not explain what elements of justice give rise to this claim. For example, does the need for such institutions arise from the demands of human rights? Or capabilities? Or needs? For example, the ILO claim that "... the notion of a social protection floor is anchored in the fundamental principle of social justice, and the specific universal right of everyone to social security and to a standard of living adequate for the health and well-being of themselves and their families” (ILO 2011, p. xxiv). However, quite what this principle of social justice would entail is not clarified. To claim that something is a matter of social justice does not explain what justice means in this context. Further, a claim that something is a matter of human rights represents a moral claim that generates obligations on others. However, quite who these “others” are is also not immediately or obviously clear.

\footnotetext{
${ }^{11}$ See, for example, Dworkin (2003, 1981), Tan (2004), and Arneson (2004).

${ }^{12}$ See Tan 2004
} 
Although there may be debate on the specific principles of justice, it is clear that there are strong arguments to support the establishment of institutions that would mitigate shared risks and human vulnerabilities. However, if ought implies can, then there may be difficulties in proposing the implementation of such institutions in a number of countries that simply do not have the capacities to invest and build such institutions immediately. Thus a decision must be taken to determine where to invest limited resources, and which constituencies to prioritise. These are normative issues concerning who ought to be targeted, what instruments will be most efficient and effective, and how to prioritise the competing interests and demands of different groups. In order for states to build capacities, they require investment in the highest revenue generating instruments, however, these are least likely to bring immediate relief to those most in need. At the same time, investment in the most vulnerable through non-contributory social protection programmes such as cash transfers, pensions, child benefits and so on, bring immediate and targeted relief to those most in need, but are ultimately unsustainable in the absence of reciprocal arrangements or a functioning contributory system. It might seem as though there is a tension between the demands of efficiency and the demands of equity. Thus, institutions of social insurance and protection are an appropriate subject matter for principles of justice, both to guide in the selection of the most appropriate instruments, and to evaluate outcomes of these arrangements.

As a first step, it could be argued that there is a duty on the donor community and states to support the establishment of such institutions, on the basis of basic justice. There is a deep unfairness that a person's place of birth will determine the level of security they experience during the course of their lives. From the perspective of basic justice, it would seem reasonable to suggest that all states should, as Rawls has argued, “... assist in the establishment of just arrangements when they do not exist, at least when this can be done with little cost to ourselves” (1971, p. 334).

There are pluralities of philosophical and political perspectives that can be drawn upon to defend the establishment of social protection mechanisms. For example, such systems can be defended on the basis of rights, as per the ILO position, or on the basis of capabilities and basic needs.

There are many rival conceptions of justice that could be examined and applied within this debate, including utilitarianism which gives priority to efficiency when seeking to maximise the value of utility; and liberal egalitarianism, which argues that inequalities can only be justified if they work to the benefit of the worst off (John Rawls, 1971; Brian Barry, 1989). Perhaps the most influential principle of social justice concerning matters of equity 
within modern market economies is John Rawls’s “Difference Principle” which states that "Social and economic inequalities are to satisfy two conditions. First, they must be attached to offices and positions open to all under conditions of fair equality of opportunity; and second, they must be to the greatest benefit of the least advantages members of society" (Rawls, 1993,p. 291).

The difference principle is based upon two core assumptions. Firstly, that circumstances of reciprocity exist and that these are sufficient to ground shared principles; and secondly, that such principles can be the subject of public reasoning and debate. It is around this matter that post-2015 public debates and dialogue seem to have found some consensual space. There seems to be a growing political consensus around a limited number of liberal egalitarian principles of justice that the new goals should ensure that no-one is left behind. For example, the UN HLP report demands a "transformative shift" in the international development policy agenda that "leaves no one behind", and supports the growth of a "global partnership", on the basis of global reciprocity and solidarity. Thus, there seems to be a growing political consensus on the ethical basis that will guide the international development agenda following the MDGs. This ethical basis seeks to utilise efficient solutions to invest in equity, and socially optimal arrangements. It is this basic requirement that we use to inform and defend the systems of social protection developed here. In particular, it is this requirement that connects efficient, contributory social protection systems to non-contributory instruments, and increasing social equity in the theoretical section of this paper.

There are also strong social reasons to justify the implementation of social protection instruments in locations that currently lack such structures. From a historical perspective, the experience of industrialisation, development, and urbanisation experienced in the Global North through the nineteenth and twentieth century led to the breakdown of traditional structures of social protection through families and communities. Over time, high income locations, characterised by predominantly urban populations and smaller families, developed more formal, state regulated and managed structures and instruments to provide security and protection from the slings and arrows of fortune to their populations.

With the rapid speed of urbanisation experienced in many low and middle income countries in the opening decades of the twenty-first century, it is emerging that traditional practices are breaking down, or are less effective as large numbers of people move to the cities to find work. This prompts a pressing need to develop new institutions and instruments to support migrants and urban communities that do not have traditional connections of 
solidarity and communal links upon which they can fall back. Rising poverty in urban locations has rapidly moved to the fore in research conducted by organisations such as Oxfam International who have highlighted the demographic shifts from rural to urban as a cause for concern requiring fresh instruments and interventions. They have highlighted the fact that “... there are more people with incomes under \$1.25 a day living in India than in all of sub Saharan Africa” (http://www.oxfam.org/sites/www.oxfam.org/files/oxfam-strategic-plan2013-2019.pdf: 13). These are locations where international NGOs typically do not have as great a presence, where they would not be as heavily engaged in the provision of public goods and services, and would usually not have the capacities to provide such public goods and services to this rapidly expanding population. This claim is supported in both the MDG and World Bank 2013 reports on global poverty levels. Thus, from a social perspective, as communities shift and change, and rapid urbanisation continues, new systems and structures are required to maintain, or support in the development of, social cohesion, inclusion, and solidarity. The absence of such systems increases the probability of crimes against property, corruption, violence, and, ultimately, sustainable economic development.

More recently, empirical literature has linked the concept of social protection not only with responsibility, but also with opportunity. For example, Gentilini and Were Omamo have found that the concept is now linked with a wider range of motivations and justifications including “... macroeconomic stabiliser, humanitarian responses, from risk management, to promoting social justice” (2011, p.329). As Gentilini and Were Omamo note, many risks are predictable, and so “... a corresponding predictable level of support is required to address needs ex ante, rather than ex post emergency assistance"(2011, p. 334).

In high-income locations, elaborate social protection infrastructures have evolved to insure people against shocks and periods of poverty (income and asset loss). However, in less developed countries and regions, exposure to shocks, even minor shocks such as an illness or a temporary loss of employment, leave the majority of the global population in a state of material insecurity and vulnerable, to varying degrees, to a descent below the poverty threshold. Even those within employment may not be fully protected. As the ILO argue, “... not all forms of employment guarantee an escape from poverty, and indeed, having a job certainly does not mean that one cannot be poor" (2009, p. 4). Income security is an essential, instrumental factor in enabling individuals and households to move out of poverty, but it is not sufficient to protect them against descent below the poverty threshold. According to the ILO report (2011) “... the recent economic crisis has demonstrated the importance of structural progress towards extending social protection in a coherent and coordinated 
manner at national and local levels. Social protection measures have cushioned the impact of the crisis among the vulnerable population, served as a macroeconomic stabiliser fuelling demand and enabled people to better overcome poverty and social exclusion in developing and developed countries" (2011, p. xii).

Protection and confidence is critical to a well-functioning economy. According to a recent MDG review report, “... people are more likely to make long-term investments when they feel secure on their property." ${ }^{13}$ Evidence from European welfare states indicates that people are more likely to spend, rather than save; to invest in their families (through health and education), and their futures, and this contributes directly to sustained economic growth. Such growth then generates a platform for further investment in social institutions and protection instruments to ensure that no constituencies are excluded. Thus, social insurance and protection are required for the promotion of just economic growth.

Finally we look at political motivations and justifications for building social protection instruments, including social transfers and insurance schemes. As the primary duty-bearer with responsibility for the protection and fulfilment of legal rights within their constituencies, states would be required to build institutions and systems to support their citizens and their economies. As states continue to support and endorse international declarations on the rights of their populations, building capacities in this area is one way in which states can realise their responsibilities and thus the rights of their citizens.

There is much evidence to suggest that lower-income states have lower levels of state legitimacy and social trust, as the state is less involved in delivering public good services to the general population. Investing in social insurance schemes that can generate income for social transfers offers one way in which states can build legitimacy and social trust among their populations.

As the ILO has argued, and many economists and theorists would agree, there is a requirement to protect human and social capital and infrastructure from natural and social contingencies. Experience in high-income states demonstrates that over time, social expenditures on social protection can become sustained and sustainable as they protect economic growth from temporary external macroeconomic shocks that can contribute to longer term damage. Insurance can then be understood as a social, political, and economic stabiliser.

\footnotetext{
${ }^{13}$ United Nations High Level Panel of Eminent Persons, A new global partnership: eradicate poverty and transform economies through sustainable development (New York, 2013), 33 (hereafter cited as UN HLP, New global partnership), http://www.un.org/sg/management/pdf/HLP_P2015_Report.pdf (01 July 2013).
} 


\title{
IV Theory of Using Natural Inequality for Efficiency and Equity Gains
}

\author{
Within Country
}

While efficient social insurance instruments can stem fresh inflows into transitory poverty, it does not necessarily address the multi-dimensional manifestations of structural poverty. Further steps are required to address these issues. Efficient insurance instruments can reduce fresh inflows into poverty and over time, they offer a resource generating opportunity (via taxation) for increased resource redistribution through non-contributory instruments, thereby targeting the most vulnerable and excluded populations. With socially oriented policies and institutions, efficient outcomes for the non- poor can lead to more equity for the most vulnerable. Efficiency and equity gains are interdependent concepts in a general equilibrium framework where states have zero tolerance for poverty in any of its manifestations.

Since the 1990s, particularly in the post-2015 discussions, the ILO has been developing an analytical and policy framework to support individual states to implement what they have termed "social protection floors". Social protection is a key element of national strategies to promote human development, political stability and inclusive growth. The ILO Social Protection Floors Recommendation, 2012 (No. 202), reflects a consensus on the extension of social security between governments and employer and worker organisations from 185 countries at all levels of development. Further, the roll-out of social protection floors is endorsed by the G20 and the United Nations. It includes guarantees of:

1. Basic income security, in the form of various social transfers (in cash or in kind), such as pensions for the elderly and persons with disabilities, child benefits, income support benefits and/or employment guarantees and services for the unemployed and working poor;

2. Universal access to essential affordable social services in the areas of health, water and sanitation, education, food security, housing, and others defined according to national priorities (ILO, 2011: xxii).

The ILO is working directly with states to develop national adaption strategies, to select and introduce the most appropriate floors on a phased basis - 'The term "social 
protection floors", in the plural, refers to national adaptations of the global approach to country-specific circumstances.' (ILO, 2011: xxiii).

According to the ILO, there are two steps to the extension of their social protection framework that includes both social security and social protection dimensions. First, they recommend the extension of a "... basic set of social guarantees for all (horizontal dimension)" and second, "the gradual implementation of higher standards (vertical dimension)". Thus, although they do not prescribe to states the precise steps and content of this model, they do advocate a bottom up approach, starting off with non-contributory social protection instruments.

However, it is possible to identify two potential problems with this approach - first, beginning with non-contributory mechanisms prioritises equity over efficiency, and risks fiscal unsustainability; and second, the state based nature of this approach gives rise to new risks and missed opportunities. There is increased potential for inter-state problems where immigration from neighbours could undermine good policies (Collier, 2007). There are also missed opportunities where greater efficiencies can be gained by capitalising on the cross state demographic structures, incomes, and their different exposures to common risks.

On the first potential problem, the proposed extension of this solution, through graduated sequencing from bottom to top, may be problematical in a number of low-income states in particular. There is a potential problem of fiscal sustainability. It assumes states have the resource capacity to engage in large-scale redistribution on an ongoing basis. ${ }^{14}$ Fundamentally, this prioritises equity over efficiency. It also fails to acknowledge the vulnerability of the non-poor who are at risk of descent below the poverty line. Such a sequencing of steps fails to stem the tide of fresh inflows below the poverty threshold.

Although it is often assumed that there are tensions between efficiency and equity such that the most equitable solutions may be less efficient, and the most efficient solutions may lack any consideration of equity and matters of distribution, an examination of the first and second welfare economics theorems would suggest that this need not be the case.

The first theorem of welfare economics sets the criterion of efficiency as its evaluative framework, where a state of affairs is defined as "Pareto Efficient" if it is the case that compared with it, “... no one's utility can be raised without reducing someone

\footnotetext{
${ }^{14}$ It is important to note that the 2011 report does acknowledge the requirement for additional fiscal supports through targeted Official Development Assistance (ODA) for countries with the highest dependent populations for a defined period of time. However, how countries would sustain such transfers after this defined period of time is unclear.
} 
else's utility” (Sen 1993, p. 520). As Sen observes, using a Pareto comparison to measure efficiency is only concerned with the matter of efficiency. "This criterion takes no interest whatsoever in distributional issues, which cannot be addressed without considering conflicts of interest and of preferences. Some further criterion is clearly needed for making social welfare judgements with a greater reach.” (1999, p. 352). Thus, designing a "Pareto Efficient” system of social security for the non-poor to mitigate the risks of falling into poverty in the presence of uncertain external shocks is an important first step in the process.

The second theorem of welfare economics, on the other hand, is concerned with matters of distribution and equity. This states that “... every Pareto efficient outcome is a competitive equilibrium at some set of prices and with respect to some initial distribution of a given resource. That is, no matter which Pareto efficient state we specify, it is possible to have a competitive market equilibrium yielding precisely that state, by choosing the initial distribution of resources appropriately." (Sen 1993, p. 520). So, under ideal conditions, this theorem would require a radical egalitarian redistribution of resources across the entire population. However, given our contemporary non-ideal circumstances, and the distinct absence of political or social consensus to build towards the first best option, that is, to redistribute assets fairly across the population (land, jobs, company ownership and resource ownership), a second best possible alternative is then to invest in public goods and redistribution via taxation and social protection. Thus, according to these fundamental theorems, although equity is not necessary for Pareto efficiency, Pareto efficiency is necessary for social optimality (Sen, 1993, p. 520).

The link between efficiency and equity is examined within the philosophical literature on this subject. There is little disagreement with Sen's claim above, and it is widely assumed within the liberal egalitarian tradition that states require the capacities, including a well-functioning and sustainable tax base, to engage in social transfers to the most vulnerable. This solution directly reduces the vulnerability of the "non-poor" (yet also those at risk of transitory poverty) through the provision of insurance schemes that can allow for the protection of assets against stochastic risks, and can indirectly create the conditions where vulnerabilities of the poor (or those experiencing structural poverty) can benefit through social transfers and investment in public goods and services.

This approach seeks to exploit existing inequalities in the distribution of assets and unequal risk exposures to generate an insurance market that mitigates asset loss with Pareto efficient outcomes thereby creating asset security. The institutions required to protect assets/incomes with insurance create a basis for further social transfers. This suggests 
building the system from the top and the bottom of stairs simultaneously, thereby using natural inequalities and social advantages to reduce social inequality and increase equity across a much wider population. An approach to social protection that is solely based on social transfers and not on sustainable contributory funds by households and companies of various forms has the potential to fail.

\section{Global Approach}

Further, increased capacity building within states is also required to enable states to underwrite and run sustainable contributory and non-contributory models. Moreover, this would present an opportunity for global enterprise and governments to run and support global social protection for all.

There are at least four reasons to explain why a blended global solution would be more appropriate and efficient than a purely domestic solution. (i) There are significant problems for states to sustain social protection and security systems if they have a demographic imbalance - too many young people or too many old people. The global demographic structure provides an opportunity to balance out this inequality to the benefit of all participants. (ii) Given the nature of external and internal shocks, exposure to certain forms of vulnerability is highly concentrated in particular locations. As such, a global solution would fragment the concentration of vulnerabilities and spread the risks across a wider region. (iii) Differentiated global income structures - while an analysis of markets and risk inside countries may lead to partial coverage creating bigger social returns to household income for richer constituencies, the global picture would allow a greater opportunity of full coverage. Finally, (iv), there are strong political reasons for supporting such an approach. According to research conducted by the ILO, income inequality, insecurity, and a lack of social insurance and protection mechanisms correlate with higher levels of social and political instability. Such instability has both intra- and inter-state consequences in an interconnected, interdependent world. As such, in the interests of what might be termed the "enlightened self-interest of states", such a solution offers a pathway out of transitory poverty through shared social insurance and towards a sustainable basis for non- contributory social transfers and distributions at the individual and household levels.

On this basis, it can be argued that the opportunity for Pareto efficiency required for socially optimal arrangements is more likely to be achieved in a global rather than domestic population base. Beginning with contributory instruments, generated through employer and employee social insurance contributions, one can potentially build a system of sustainable social transfers across a global population. Rather than promote a model of Tobin taxes on 
company profits to fund a global social protection fund, such a fund can be generated by direct contributions from employers and employees. This basic "human" infrastructure could drive economic and social development in the same upward direction.

To provide basic social protection for the global population, ILO estimates suggest that this fund would cost approximately 10 per cent of global GDP. This is clearly more ambitious than 0.7 of 1 per cent of GDP which is the target of ODA. However, this is feasible through financial engineering of a social insurance market underwritten by governments. This would represent a substantial shift away from "business as usual" development solutions that seek to rely on domestic governments to fund social transfers with limited domestic taxation. Rather, the solution proposed suggests blending public and private sector partnership to protect financial capital and human capital, and develop markets for products in companies and households to invest and save, confident that they are insured against unforeseen events. Such an approach would be consistent with an emerging global political language around partnership and reciprocity in addition to solidarity and the requirement to "leave no one behind". The underlying assumptions of global social protection solutions are increasing levels of global solidarity and recognition of the mutual interdependencies and reciprocal relations between individuals and states. The global scheme will work to the benefit of all to ensure "no one is left behind” as the least advantaged can benefit from Pareto efficiency in social security that create opportunities for redistribution using social transfers.

\section{Potential objections:}

We have argued that using social protection to provide insurance to the non-poor population could drive Pareto efficient improvements, such that no one will be made worse off. The availability of social insurance to non-poor populations would be likely to stem the inflow of workers into poverty, build capacity in state institutions and systems, build legitimacy and trust, and at the same time provide the foundation for a larger tax base and a capability to run national social transfer schemes to the benefit of the poorest and most vulnerable.

Yet our solution immediately gives rise to a range of potential objections such as first, that it would reinforce existing inequalities and unequal power structures; second, that it would deepen vertical benefits from social security, benefitting the most advantaged; and 
third, related to these points, that it would lie in conflict with emerging development principles to target the least advantaged and ensure no one is left behind.

One potential risk with this approach is that it could be used to build political constituencies and secure political gain in terms of elections and fiscal gain when targeting social insurance at formal employment or households with higher willingness to pay and high risk aversion. This could have the effect of enabling higher income households to insure themselves against various risks thereby leading to much better private outcomes, for example, in education and health, for their level of income. This is empirically borne out within and between nations. There is evidence that some governments build legitimacy from the top of the staircase leaving the poorest behind thereby reinforcing inequalities in society. Some democratic electoral systems and the presence of ethno-regional voting cleavages within countries might encourage such an outcome.

However, it is important to clarify that the central thesis of the argument presented here is that tackling transitory poverty would provide a basis for investment in more equitable and extensive social protection measures. Wide scale social insurance is proposed as a solution to the problem of transitory poverty. However, this is a first step. Additional policies and interventions are then required to tackle structural poverty and exclusion, to secure the fair distribution of benefits across a community, and to ensure that no one is left behind. This solution need not be inconsistent with the moral principles emerging from the post-MDG political dialogue. If the benefits of such a system are appropriated by cooperating states and redistributed to the wider community through appropriate non-contributory schemes targeted at those in structural poverty, then the guiding principle to leave no one behind can be achieved and sustained over time.

\section{Conclusion}

Conceptualisations of poverty and 'the poor' as a minority group in a state of continuous dependency, identifiable by region and demographic cannot capture the dynamic reality of poverty and the everyday risks to which people are exposed. Using a flow analysis (inflow and outflow) of poverty, rather than a stock analysis, we have explained why poverty is more appropriately understood as a dynamic, with the majority of people flowing in and out of poverty for short durations. Distinguishing between structural and transitory poverty then gives rise to a focus on the identification of multiple constituencies in the wider population including the permanently poor; sometimes poor; and non-poor. Internal and 
external shocks, including economic and environmental shifts, and risks such as ill-health, can affect any individual, household, or population in a non-predictable way, and can lead to loss of livelihood and a decent into poverty. We have argued that these basic facts of human life give rise to the requirement to develop robust social protection and insurance mechanisms to mitigate the risks of a descent into poverty.

Using a flow analysis explains why attempts to tackle poverty which ignore the dynamic nature of the concept and the exposure of a large proportion of the global population to transitory poverty are likely to fail. As a solution to the problem of transitory poverty we have argued that a global social protection framework would produce both an efficient and equitable solution to the current status of 5.1 billion people living in conditions of uncertainty and insecurity.

However, the approach defended here differs from the ILO and other organisations that focus on the establishment of social protection floors, arguing that such approaches are not fiscally sustainable. Rather, our approach seeks to exploit existing inequalities in the distribution of assets and unequal risk exposures to generate an insurance market that mitigates asset loss with Pareto efficient outcomes thereby creating asset security. The institutions required to protect assets/incomes with insurance create a basis for further social transfers. We have argued that it is necessary to build the institutions and systems from the top and the bottom of stairs simultaneously, thereby using natural inequalities and social advantages to reduce social inequality and increase equity across a much wider population.

By distinguishing between transitory and structural poverty, this solution first, seeks to stem fresh inflows from the "sometimes poor" and "non-poor" into extreme poverty by providing protections against stochastic risks to which all human beings are exposed; second, it seeks to use efficient outcomes to increase equity through a wider distribution of the gains of this social cooperation. This solution uses the power and reach of market-mechanisms to expand the reach of social cooperation and mutual, reciprocal gain through shared arrangements. It pushes the post 2015 agenda beyond the idea of the bottom billion. 


\section{References}

ARNESON, R., (2008) "Rawls, Responsibility, and Distributive Justice” in SALLES and WEYMARK (eds) Justice, Political Liberalism and Utilitarianism Cambridge: Cambridge University Press

Arneson R (2004) Luck Egalitarianism Interpreted and Defended. In Philosophical Topics, 32:1 pp. 1-20.

BACHELET, M., 2011. Social Protection Floor for a Fair and Inclusive Globalisation, Geneva: International Labour Office.

BARRY, B, 1989. “Chance, Choice and Justice”, in Liberty and Justice, Oxford: Oxford University Press, pp. 142-58 (229-238).

BEHRENDT, C. and K. HAGEMEJER, 2009. "Can Low-Income Countries Afford Basic Social Security?” OECD publication, Promoting Pro-poor Growth: Social Protection.

CHEN, S. and M. RAVILLION, 2008. "The Developing World is Poorer Than We Thought, But No Less Successful in the Fight Against Poverty”, Available at http://econ.worldbank.org/external/default/main?pagePK=64165259\&theSitePK=469372\&pi $\underline{\mathrm{PK}=64165421 \& \text { menuPK}=64166093 \& \text { entityID }=000158349 \_20100121133109 \& \mathrm{cid}=\text { decresea }}$ $\underline{\mathrm{rCh}}$

COLLIER, P., 2007. The Bottom Billion, New York: Oxford University Press.

DEVEREUX, S. and F. LUND, 2010. "Democratising Social Welfare in Africa” in V.

Padayachee (ed.), The Political Economy of Africa, Abingdon: Routledge.

DEVEREUX, S. and R. SABATES-WHEELER, 2004. "Transformative Social Protection”, IDS Bulletin, Vol. 38, pp. 1-7.

DEVEREUX, S., F. ELLIS and P. WHITE, 2009. Social Protection in Africa, Cheltenham, UK and Northampton, MA, USA: Edward.

DUFFIELD, M., 2010. “The Liberal Way of Development and the Development Security Impasse: Exploring the Global Life-Chance Divide”, Security Dialogue, Vol. 41, pp. 53-75.

Dworkin R (2003) Equality, Luck and Hierarchy. In Philosophy and Public Affairs 31 pp. 190-198.

Dworkin R (2000) Sovereign Virtue. London: Harvard University Press.

Dworkin R (1981) What is Equality? II. Equality of Resources. In Philosophy and Public Affairs 10 pp. 283-345. 
GENTILINI, U. and S. WERE OMAMO, 2011. "Social Protection 2.0: Exploring Issues, Evidence and Debates in a Globalising World”, Food Policy, Vol. 36, pp. 329-340.

GROOTAERT, C., R. KANBUR and G.-T. OH, 1995. “The Dynamics of Poverty: Why Some People Escape from Poverty and Others Don’t - An African Case Study”, World Bank: Policy Research Working Paper.

INTERNATIONAL LABOUR OFFICE, 2009. Social Security Policy Briefings: Social Security For All; Investing in Social Justice and Economic Development; ILO Geneva available at http://www.socialprotectionfloor-gateway.org/files/Social_security_for_all.pdf

INTERNATIONAL LABOUR OFFICE, 2011. Social Protection Floor for a fair and inclusive globalisation (2011), accessed 27 August 2013. See http://www.ilo.org/global/publications/books/WCMS_165750/lang_en/index.htm

INTERNATIONAL LABOUR OFFICE, 2014. World Social Protection Report, "Building Economic Recovery, Inclusive Development and Social Justice”, Geneva.

KRISHNA, A., 2007. “The Dynamics of Poverty”, 2020 Focus Brief on the World's Poor and Hungry People, International Food Policy Research Institute, Washington, USA. http://www.ifpri.org/sites/default/files/publications/beijingbrief_krishna.pdf

MILLENNIUM DEVELOPMENT GOALS REPORT, 2013. Available at http://www.un.org/millennium goals/pdf/report-2013/mdg-report-2013-english.pdf

RAWLS, J., 1971. A Theory of Justice, Cambridge, MA: Belknap Press of Harvard University Press.

RAWLS, J., 1993. "Political Liberalism”. The John Dewey Essays in Philosophy, New York: Columbia University Press.

SEN, A., 1993. "Markets and Freedoms: Achievements and Limitations of the Market Mechanism in Promoting Individual Freedom”, Oxford Economic Papers, New Series, Vol. 45, No. 4, pp. 519-541.

SEN, A., 1997. "Inequality, Unemployment, and Contemporary Europe” in International Labour Review, Vol. 136, No. 2, pp. 155-171.

SEN, A., 1999. "The Possibility of Social Choice”, The American Economic Review, Vol. 89, No. 3, pp. 349-378.

Tan, K. C. (2004) Justice without borders. Cambridge UK.: Cambridge University Press.

TANNER, T. and T. MITCHELL, 2008. "Introduction: Building the Case for Pro-poor Adaptation” in T. Tanner and T. Mitchell (eds.), Poverty in a Changing Climate, IDS Bulletin 39, pp. 1-5.

UNITED NATIONS HIGH LEVEL PANEL OF EMINENT PERSONS, 2013. A New Global Partnership: Eradicate Poverty and Transform Economies Through Sustainable 
Development, (New York, 2013), 33 (hereafter cited as UN HLP, New global partnership), http://www.un.org/sg/management/pdf/HLP_P2015_Report.pdf(01 July 2013).

WORLD BANK DEVELOPMENT INDICES, 2008. Available at http://data.worldbankorg/sites/default/files/wdi08.pdf (p. 24).

WORLD BANK DEVELOPMENT REPORT, 2013. Available at http://siteresources.worldbank.org/EXTNWDR2013/Resources/82580241320950747192/8260293-1322665883147/WDR_2013_Report.pdf

WORLD BANK DEVELOPMENT REPORT, 2014 "Risk and Opportunity Managing Risk for Development” World Bank, Washington. 